\title{
Permo-Triassic Source Rock Assessment by Inherited of the Triassic Oils in Kuwait
}

\author{
Rita Andriany ${ }^{1}$ and Awatif Al-Khamiss ${ }^{1}$ \\ 1 Geochemistry Unit of Exploration Studies - Exploration Group of Kuwait Oil Company
}

Two majors of the younger petroleum systems in Jurassic age of Najmah-Najmah (!) and Cretaceous age of Makhul-Burgan (!) have been identified and characterized. Crude oils trapped in the older reservoir of Triassic age at Mutriba and Kra Al-Maru fields showing different characters compared to the oils in younger systems. Biomarker, diamondoid, and carbon isotope are the most resistant compounds throughout the geological processes. Hence, the specific characteristics of crude oils trapped in Triassic reservoirs can be utilized for the source rock tracking. Genetic characters of the parent rock will be inherited to the oils produced. Oil and source rock are having a reciprocal relationship, by determining nature of the source rocks, the produced oil characters can be predicted and vice versa.

Concentration of carbon isotopes show a specific pattern characterized by declined in value with increasing age of the source of organic matter. Oils derived from Cretaceous source had higher levels of carbon isotopes values compared to oils sourced from the Jurassic. The isotopic concentrations of oils trapped in Triassic reservoirs are significantly low which almost two per mil lower than oils generated from Jurassic source rock. Hence, we can assume that oils derived from more mature source rocks will be decreased or depletion in their carbon isotope concentrations. Determining of the isotopic concentration in reservoirs allows for genetic tracing of the source origin of the organic matters (Prizhofer et.al, 2000, Schoell et.al., 1984). Schoell (1984) on his investigation from the Mahakam Delta data found that the mature source rock will be generate kerogens or oils similar in their isotopic values. The low isotopic concentrations of oil trapped in Triassic reservoirs as a clue that may generated from more mature parent rocks, most probably from the older source rocks in the Permo - Triassic systems

Triassic oils are characterized by low ratios of the pristane/phytane and pristane/nC17 less than 1 and 0.4 , respectively and high ratio of phytane/nC18 $(\geq 0.4)$ indicates were generated from carbonate source rocks deposited in marine environment. Other evidences of the Triassic oils exhibit in decreasing of the biomarker concentrations and increasing amount of the diamondoid by maturity increased. Whereas, the characters of the oils derived from younger source rocks are showing opposite pattern. Ratios of the regular steranes $\mathrm{S} /(\mathrm{S}+\mathrm{R})(\mathrm{C} 29 \alpha \alpha \alpha)$ have been reached the equilibrium level. Biomarker and diamondoid evidences can be interpreted that oils trapped in Triassic reservoirs have been generated from source rocks with higher maturity levels.

Detailed study for Triassic Source Assessment from extracts of four (4) of potential source rocks including Minjur, Jilh, Sudair, and Khuff have been performed as conventional methods several years ago. However, for quick look in exploration appraisal, crude oils assessment for determining source rock characteristic and distribution is a new approach. This geochemical inversion technique is believed would be the major option since it proved fast and cheaper compared to the conventional methods.

Result of crude oil assessment can be concluded that the Triassic oils have been generated from the carbonate source rock of Permo - Triassic age that deposited in anoxic marine depositional environment. These potential source rocks are believed of having sufficient of the hydrocarbons richness and reached proper maturity levels prior expulsed and trapped in 
Triassic reservoirs. Pod of the active kitchen for Permo - Triassic systems are potentially located around or nearby the areas of the Triassic wells which is interpreted similar to pod of Jurassic's active kitchen.

Crude oil assessment as "geochemical inversion" methods can be performed if we have reliable and proper standard characteristics (oils and source rocks) which obtained from oil-oil to source correlation in the younger and/ or older petroleum systems of similar basin. Sophisticated geochemical techniques including gas chromatography (GC), gas chromatography mass spectrometry (GCMS) for saturate and aromatic, and isotopic concentrations (carbon, sulfur, and deuterium) are standard analyses required for oils assessments. Finally, for quick exploration appraisal, this geochemical inversion technique are proven accurate, fast, and cheaper approach to reduce exploration cost compared to the conventional method of the source rock assessment from extracts.
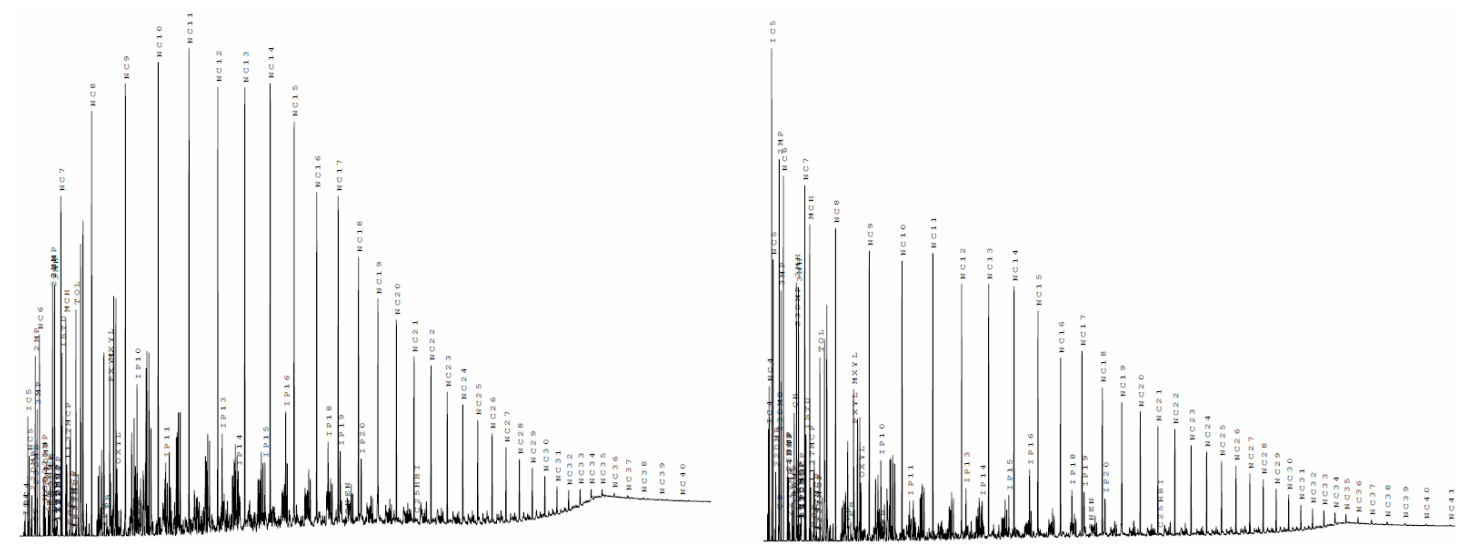

Figure 1: Distribution of the normal-alkanes and isoprenoids of Triassic oils from gas chromatography analysis.

\section{References:}

Prinzhofer, Alain, Mello, Macio R., and Takaki, Tikae. "Geochemical Characterization of Natural Gas: A Physical Multivariable Approach and its Applications in Maturity and Migrations Estimates”. AAPG Bulletin Vol.84 No.8 (August 2000). 1152 1172. G

Schoell, Martin. "Recent advances in Petroleum Isotope Geochemistry". Organic Geochemistry Vol. 6 (1984). p. 645-663. 